\title{
Thermodynamic Description of the Ag-Pb-Te Ternary System
}

\author{
Wojciech Gierlotka, Joanna kapsa, and Krzysztof Fitzner
}

(Submitted June 10, 2010; in revised form July 13, 2010)

\begin{abstract}
Tellurium is an unwanted admixture in silver thus it is important to optimize tellurium removal from Ag by controlling its distribution between the liquid, slag and gaseous phases. Consequently, the knowledge of the state of thermodynamic equilibrium which determines the distribution of tellurium between these phases is very important. For its prediction it is necessary to know the thermodynamic description of every phase. In the present paper an attempt has been made to work out a thermodynamic description of the Ag-Pb-Te system. This description is based on literature information and the CALPHAD method. Then, the influence of lead on the vapor pressure of tellurium is analysed.
\end{abstract}

Keywords ternary phase diagram, thermodynamic modeling, vapor pressure tion of tellurium between these phases is very important. In the present paper an attempt has been made to work out a thermodynamic description of the Ag-Pb-Te system, and then to predict the influence of lead content in silver on the vapor pressure of tellurium in the gaseous phase.

\section{Thermodynamic Description of the Phases}

During the electrolytic refining of copper a by-product known as anodic slimes is obtained and collected in anodic compartments. It is a valuable source of silver, gold, platinum group metals, but also it contains lead, bismuth, antimony, selenium and tellurium. The amount of tellurium in copper anode slimes has been reported to vary from 0.3 to $3 \%$, though sometimes it can reach the level of $10 \% .^{[1,2]}$ It occurs principally in solid solutions, but, if the Te content is high enough telluride phases can also be formed.

After acid pretreatment the slime is melted under reducing conditions in a reverberatory furnace. The product of this so-called Kaldo process is an alloy containing mainly lead and silver with the additions of a number of solutes. This alloy is next oxidized and during this operation solutes are transferred into the slag phase. Noble metals remain in silver while selenium and some tellurium are removed after oxidation in the form of gaseous species. However, tellurium may still be present in silver. Needless to say, the amount of tellurium in silver exceeding $20 \mathrm{ppm}$ lowers its price and results in difficulty of selling the silver on the market. It is thus important to optimize tellurium removal from silver by controlling its distribution between the liquid, the slag and the gaseous phases. Consequently, knowledge of the state of thermodynamic equilibrium which determines the distribu-

Wojciech Gierlotka, Joanna Lapsa, and Krzysztof Fitzner, Laboratory of Physical Chemistry and Electrochemistry, Faculty of Non-Ferrous Metals, AGH University of Science and Technology, 30 Mickiewicza Av., 30-059 Krakow, Poland; Wojciech Gierlotka, Department of Chemical Engineering and Material Science, Yuan Ze University, \# 135 Yuan-Tung Road, Chungli, Taoyuan 320, Taiwan, ROC. Contact e-mail: wojtek@saturn.yzu.edu.tw.
The following phases are considered in this work: FCC A1 (Ag, Pb), Hexagonal A8 (Te), liquid, PbTe, $\mathrm{Ag}_{2} \mathrm{Te}$, $\mathrm{Ag}_{5} \overline{\mathrm{Te}}_{3}, \mathrm{Ag}_{655} \mathrm{Te}_{345}$. Detailed information about these phases is given in Table 1 and below.

\subsection{Substitutional Solution-FCC_A1 $(A g, P b)$}

The Gibbs free energy of pure elements as a function of temperature ${ }^{0} G_{i}(T)=G_{i}(T)-H_{i}^{\mathrm{SER}}$ is represented by Eq 1:

$$
\begin{aligned}
{ }^{0} G_{i}(T)= & a+b T+c T \ln (T)+d T^{2}+e T^{-1}+f T^{3} \\
& +i T^{4}+j T^{7}+k T^{-9}
\end{aligned}
$$

The ${ }^{0} G_{i}(T)$ data are referred to the constant enthalpy value of the standard element reference $H_{i}^{\mathrm{SER}}$ at $298.15 \mathrm{~K}$ and 1 bar as recommended by Scientific Group Thermodata Europe (SGTE). ${ }^{[3]}$ The reference states are: FCC_A1 $(\mathrm{Cu}$ and $\mathrm{Pb}$ ) and Rhombohedral_A7 (Sb). The ${ }^{0} G_{i}(T)$ expression may be given for several temperature ranges, where the coefficients $a, b, c, d, e, f, i, j, k$ have different values. The ${ }^{0} G_{i}(T)$ functions are taken from SGTE Unary (Pure elements) TDB v.4. ${ }^{[3]}$ Thermodynamic functions of pure elements are listed in Table 2. The FCC_A1 phases are described by the regular solution model ${ }^{[4]}$ :

$$
\begin{aligned}
G_{m}(T)= & \sum_{i} x_{i}^{0} G_{i}(T)+R T \sum_{i} x_{i} \ln \left(x_{i}\right) \\
& +\sum_{i} \sum_{j>i} x_{i} x_{j}\left(\sum_{v}{ }^{v} L_{i j}\left(x_{i}-x_{j}\right)^{v}\right)
\end{aligned}
$$


Table 1 Crystal structure of phases of $\mathrm{Ag}-\mathrm{Pb}$-Te system

\begin{tabular}{lcccc}
\hline Phase & $\begin{array}{c}\text { Pearson } \\
\text { symbol }\end{array}$ & $\begin{array}{c}\text { Space } \\
\text { group }\end{array}$ & $\begin{array}{c}\text { Strukturbericht } \\
\text { designation }\end{array}$ & Prototype \\
\hline $\mathrm{FCC} \_\mathrm{A} 1$ & $c F 4$ & $F m \overline{3} m$ & $\mathrm{~A} 1$ & $\mathrm{Cu}$ \\
$\alpha \mathrm{Ag}_{2} \mathrm{Te}$ & $m P 12$ & $P 2_{1} / c$ & $\ldots$ & $\mathrm{Ag}_{2} \mathrm{Te}$ \\
$\beta \mathrm{Ag}_{2} \mathrm{Te}$ & $c F 12$ & $\ldots$ & $\ldots$ & $\ldots$ \\
$\gamma \mathrm{Ag}_{2} \mathrm{Te}$ & $\ldots$ & $\ldots$ & $\ldots$ & $\ldots$ \\
$\gamma$ & $\ldots$ & $\ldots$ & $\ldots$ & $\ldots$ \\
$\alpha \mathrm{Ag}_{5} \mathrm{Te}_{3}$ & $h P 55$ & $P 6 / m m m$ & $\ldots$ & $\ldots$ \\
$\beta \mathrm{Ag}_{5} \mathrm{Te}_{3}$ & $\ldots$ & $\ldots$ & $\ldots$ & $\ldots$ \\
$\mathrm{PbTe}$ & $c F 8$ & $F m \overline{3} m$ & $\ldots$ & $\ldots$ \\
$\mathrm{Hexagonal}_{2} \mathrm{~A} 8$ & $h P 3$ & $P 3_{1} 21$ & $\mathrm{~A} 8$ & $\gamma \mathrm{Se}$ \\
\hline
\end{tabular}

where the $\sum_{i} \sum_{j>i} x_{i} x_{j}\left(\sum_{v}{ }^{v} L_{i j}\left(x_{i}-x_{j}\right)^{v}\right)$ part is the Redlich-Kister polynomial for the excess Gibbs free energy.

\subsection{Stoichiometric Compounds-PbTe, $\mathrm{Ag}_{2} \mathrm{Te}, \mathrm{Ag}_{5} \mathrm{Te}_{3}$, $\mathrm{Ag}_{655} \mathrm{Te}_{345}$}

Binary stoichiometric compounds $\mathrm{PbTe}, \mathrm{Ag}_{2} \mathrm{Te}, \mathrm{Ag}_{5} \mathrm{Te}_{3}$, $\mathrm{Ag}_{655} \mathrm{Te}_{345}$ are described as the line compounds using the following expression:

$G_{m}(T)=a+b T+\sum_{i} x_{i} \mathrm{GHSER}_{i}$

The polymorphic transformations of the phases $\mathrm{Ag}_{2} \mathrm{Te}$, $\mathrm{Ag}_{5} \mathrm{Te}_{3}$ and $\mathrm{Ag}_{655} \mathrm{Te}_{345}$ were neglected since no available information about these transformations in the ternary system exists.

\subsection{Associated Liquid Model}

The liquid phase is described using the association model. ${ }^{[4]}$ Since the enthalpy of mixing of the liquid phase exhibits $\mathrm{V}$-shape in $\mathrm{Pb}$-Te and $\mathrm{Ag}$-Te systems the compositions of conglomerates were chosen to be $\mathrm{PbTe}$ and $\mathrm{Ag}_{2} \mathrm{Te}$. Apart from the shape of the enthalpy of mixing, the literature information proved the existence of the liquid associates in $\mathrm{Ag}-\mathrm{Te}$ and $\mathrm{Pb}-\mathrm{Te}$ systems. Dancy ${ }^{[5]}$ and Faber $^{[6]}$ measured electrical conductivity of liquid Ag-Te and liquid $\mathrm{Pb}-\mathrm{Te}$ alloys, respectively. From their work it is clear that liquid associates exist in these solutions. Moreover, Glazov et al. ${ }^{[7]}$ showed that in the liquid $\mathrm{Pb}-\mathrm{Te}$ alloy there exists a correlation between conductivity and viscosity. This also proves the existence of the liquid $\mathrm{Pb}-\mathrm{Te}$ associates. The Gibbs energy for one mole of atoms is given by the following formula:

$$
\begin{aligned}
G_{m}^{\mathrm{Liquid}}= & {\left[x_{\mathrm{Ag}}{ }^{0} G_{\mathrm{Ag}}^{\mathrm{Liquid}}+x_{\mathrm{Pb}}{ }^{0} G_{\mathrm{Pb}}^{\mathrm{Liquid}}+x_{\mathrm{Te}}{ }^{0} G_{\mathrm{Te}}^{\mathrm{Liquid}}\right.} \\
& +x_{\mathrm{Ag}_{2} \mathrm{Te}^{0} G_{\mathrm{Ag} 2 \mathrm{Te}}^{\mathrm{Liquid}}+x_{\mathrm{PbTe}}{ }^{0} G_{\mathrm{PbTe}}^{\mathrm{Liquid}}} \\
& +R T\left(x_{\mathrm{Ag}} \ln x_{\mathrm{Ag}}+x_{\mathrm{Pb}} \ln x_{\mathrm{Pb}}+x_{\mathrm{Te}} \ln x_{\mathrm{Te}}\right. \\
& \left.+x_{\mathrm{Ag}_{2} \mathrm{Te}} \ln x_{\mathrm{Ag} 2 \mathrm{Te}}+x_{\mathrm{PbTe}} \ln x_{\mathrm{PbTe}}\right) \\
& \left.+{ }^{x s} G^{\mathrm{Liquid}}\right] /\left(1+3 x_{\mathrm{Ag}_{2} \mathrm{Te}}+2 x_{\mathrm{PbTe}}\right)
\end{aligned}
$$

\section{Experimental Information}

Taking into account the associate solution model which was used in this work for description of the ternary Ag-PbTe system, one should mention that binary $\mathrm{Pb}-\mathrm{Te}$ and $\mathrm{Ag}-\mathrm{Te}$ systems had to be also remodeled. For reoptimization of these binary systems we used exactly the same experimental sets as in our previous works ${ }^{[8,9]}$ where an ionic model was used. The binary Ag-Pb system was also recalculated using the same literature information as Lee et al. ${ }^{[10]}$ used.

Experimental information about Ag- $\mathrm{Pb}-\mathrm{Te}$ system is very limited. Enthalpy of mixing of the liquid phase was measured by Romermann and Blachnik. ${ }^{[1]}$ They measured the heat of mixing for five sections: $\mathrm{Te}-\mathrm{Ag}_{08} \mathrm{~Pb}_{02}, \mathrm{Te}-\mathrm{Ag}_{06} \mathrm{~Pb}_{04}$, $\mathrm{Te}-\mathrm{Ag}_{05} \mathrm{~Pb}_{05}, \mathrm{Te}-\mathrm{Ag}_{04} \mathrm{~Pb}_{06}, \mathrm{Te}-\mathrm{Ag}_{02} \mathrm{~Pb}_{08}$, at temperatures: 973, 1073 and $1173 \mathrm{~K}$. No information about either activities or chemical potentials of components in the ternary liquid alloys was found. The DTA information was provided by Blachnik and Gather ${ }^{[12]}$ and Blachnik and Bolte. ${ }^{[13]}$ Blachnik and Gather ${ }^{[12]}$ investigated the cross-section $\mathrm{Ag}_{2} \mathrm{Te}-\mathrm{PbTe}$. Besides DTA experiments they also identified the phases present in the system using $\mathrm{x}$-ray and metallographic methods. Blachnik and Bolte ${ }^{[13]}$ examined two isopleths in $\mathrm{Ag}-\mathrm{Pb}$-Te system. The first one is $\mathrm{Ag}_{2} \mathrm{Te}-\mathrm{Pb}$ section, and the second one is the $\mathrm{PbTe}-\mathrm{Ag}$ section. Similarly, as in previous paper, ${ }^{[12]}$ DTA, x-ray and metallographic methods were used for the determination of phase equilibria. Unfortunately, the isopleths don't agree with each other. In the cross point of the two isopleths a difference between liquidus temperatures is about $100^{\circ}$. In our case for optimization we used the information obtained from $\mathrm{PbTe}-\mathrm{Ag}$ isopleth.

\section{Optimization Procedure}

The thermodynamic parameters for all phases in the system were optimized using ThermoCalc software. ${ }^{[14]}$ For this optimization, thermodynamic data for the liquid phase, invariant reactions and phase equilibria were used. To each piece of the selected information a certain weight was given which was based on personal judgment. First, Ag-Te, $\mathrm{Pb}-\mathrm{Te}$ and $\mathrm{Ag}-\mathrm{Pb}$ binary systems were optimized, and these optimizations were incorporated into optimization of the ternary $\mathrm{Ag}-\mathrm{Pb}$-Te system. The optimization was carried out step by step in agreement with Schmid-Fetzer's et al. ${ }^{[15]}$ guideline. First, the optimization of the liquid phase was performed, and then the solid phases were assessed. All parameters were finally evaluated together to provide the best description of the system. The calculated interaction parameters are shown in Table 2. For checking of the results of optimization the system was also calculated using Pandat software. ${ }^{[16]}$

\section{Result and Discussion}

\subsection{Binary Systems}

The obtained set of thermodynamic parameters is gathered in Table 2. Calculated phase diagrams of the 
Table 2 Gibbs energies and interaction parameters of Ag-Pb-Te system

\begin{tabular}{|c|c|c|}
\hline Phase or component & Parameter & $T, \mathbf{K}$ \\
\hline Liquid & 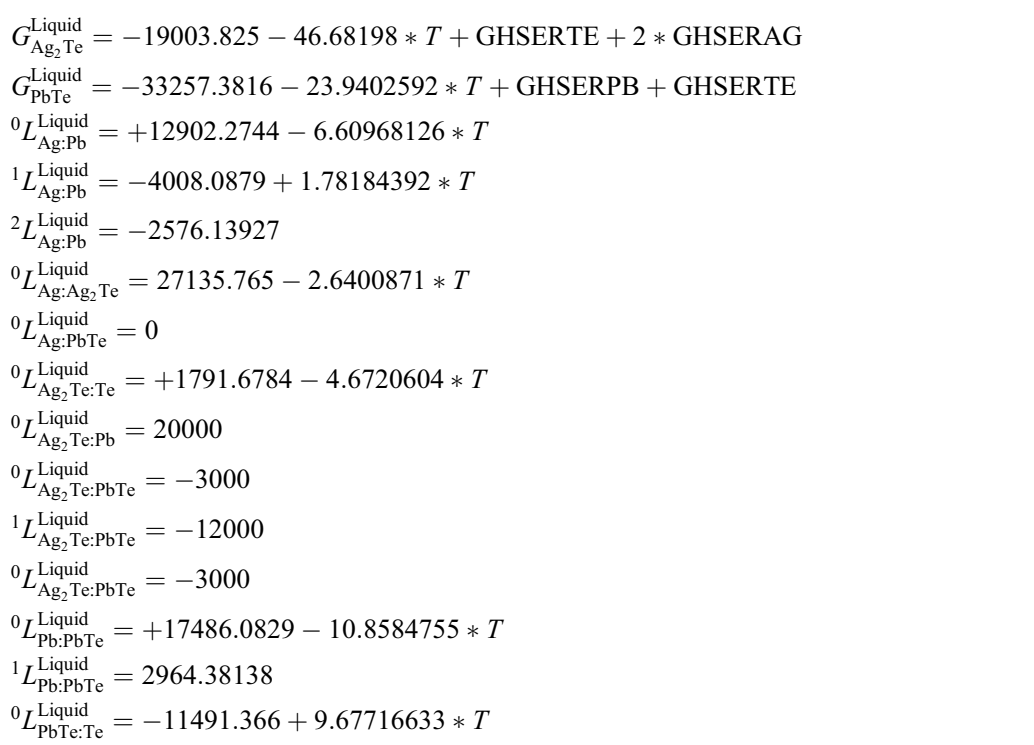 & $298.15<T<2000.00$ \\
\hline $\mathrm{Ag}_{2} \mathrm{Te}$ & $\begin{aligned} G_{\mathrm{Ag}: \mathrm{Te}} & =10128.93-12.645115 * T+0.667 * \text { GHSERAG } \\
& +0.333 * \text { GHSERTE } \\
\mathrm{Ag}_{2} \mathrm{Te} & G_{\mathrm{Pb}: \mathrm{Te}}^{\mathrm{Ag} 2 \mathrm{Te}}=2000+0.667 * \mathrm{GHSERPB}+0.333 * \text { GHSERTE } \\
{ }^{0} L_{\mathrm{Ag}, \mathrm{Pb}: \mathrm{Te}}^{\mathrm{Ag} T}= & -15000\end{aligned}$ & $298.15<T<2000.00$ \\
\hline $\mathrm{Ag}_{5} \mathrm{Te}_{3}$ & $\begin{aligned} G_{\mathrm{Ag}: \mathrm{Te}}^{\mathrm{Ag}_{5} \mathrm{Te}_{3}=-} & 11516.052-9.0707833 * T+0.62 * \mathrm{GHSERAG} \\
& +0.38 * \mathrm{GHSERTE}\end{aligned}$ & $298.15<T<2000.00$ \\
\hline $\mathrm{Ag}_{655} \mathrm{Te}_{345}$ & $\begin{aligned} G_{\mathrm{Ag}: \mathrm{Te}}^{\mathrm{Ag}_{65} \mathrm{Te}_{345}}= & -10429.085-11.872022 * T+0.655 * \text { GHSERAG } \\
& +0.345 * \text { GHSERTE }\end{aligned}$ & $298.15<T<2000.00$ \\
\hline $\mathrm{PbTe}$ & $G_{\mathrm{Pb}: \mathrm{Te}}^{\mathrm{PbTe}}=-76063.2138+9.67716633 * T+\mathrm{GHSERPB}+\mathrm{GHSERTE}$ & $298.15<T<2000.00$ \\
\hline FCC_A1 & $\begin{array}{l}{ }^{0} L_{\mathrm{Ag}, \mathrm{Pb}}^{\mathrm{FCC}-\mathrm{A} 1}=+27610.0621-3.68528128 * T \\
{ }^{1} L_{\mathrm{Ag}, \mathrm{Pb}}^{\mathrm{FCC} A \mathrm{Al}}=-2197.271\end{array}$ & $298.15<T<2000.00$ \\
\hline \multirow[t]{6}{*}{$\mathrm{Pb}$} & $\begin{aligned}{ }^{0} G_{\mathrm{Pb}}^{\mathrm{FCC} \_\mathrm{A} 1}= & -7650.085+101.700244 * T-24.5242231 * T * \mathrm{LN}(T) \\
& -0.00365895 * T * * 2-2.4395 \mathrm{E}-07 * T * * 3\end{aligned}$ & $298.15<T<600.61$ \\
\hline & $\begin{aligned}{ }^{0} G_{\mathrm{Pb}}^{\mathrm{FCC} \_\mathrm{A} 1}= & -10531.095+154.243182 * T-32.4913959 * T * \mathrm{LN}(T) \\
& +0.00154613 * T * * 2+8.05448 \mathrm{E}+25 * T * *(-9)\end{aligned}$ & $600.61<T<1200.00$ \\
\hline & $\begin{aligned}{ }^{0} G_{\mathrm{Pb}}^{\mathrm{FCC} \_\mathrm{A} 1}= & +4157.616+53.139072 * T-18.9640637 * T * \mathrm{LN}(T) \\
& -0.002882943 * T * * 2+9.8144 \mathrm{E}-08 * T * * 3-2696755 * T * *(-1) \\
& +8.05448 \mathrm{E}+25 * T * *(-9)\end{aligned}$ & $1200.00<\mathrm{T}<2100.00$ \\
\hline & $\begin{aligned}{ }^{0} G_{\mathrm{Pb}}^{\mathrm{Liquid}}= & -2977.961+93.949561 * T-24.5242231 * T * \mathrm{LN}(T) \\
& -0.00365895 * T * * 2-2.4395 \mathrm{E}-07 * T * * 3-6.019 \mathrm{E}-19 * T * * 7\end{aligned}$ & $298.15<T<600.61$ \\
\hline & $\begin{aligned}{ }^{0} G_{\mathrm{Pb}}^{\text {Liquid }}= & -5677.958+146.176046 * T-32.4913959 * T * \mathrm{LN}(T) \\
& +0.00154613 * T * * 2\end{aligned}$ & $600.61<T<1200.00$ \\
\hline & $\begin{aligned}{ }^{0} G_{\mathrm{Pb}}^{\text {Liquid }}= & +9010.753+45.071937 * T-18.9640637 * T * \operatorname{LN}(T) \\
& -0.002882943 * T * * 2+9.8144 \mathrm{E}-08 * T * * 3-2696755 * T * *(-1)\end{aligned}$ & $1200.00<T<2100.00$ \\
\hline \multirow[t]{3}{*}{$\mathrm{Te}$} & $\begin{aligned}{ }^{0} G_{\mathrm{Te}}^{\text {Hexagonal_A8 }}= & -10544.679+183.372894 * T-35.6687 * T * \mathrm{LN}(T) \\
& +0.01583435 * T * * 2-5.240417 \mathrm{E}-06 * T * * 3+155015 * T * *(-1)\end{aligned}$ & $298.15<T<722.66$ \\
\hline & $\begin{aligned}{ }^{0} G_{\mathrm{Te}}^{\text {Hexagonal } \_ \text {A8 } 8}= & +9160.595-129.265373 * T+13.004 * T * \mathrm{LN}(T) \\
& -0.0362361 * T * * 2+5.006367 \mathrm{E}-06 * T * * 3-1286810 * T * *(-1)\end{aligned}$ & $722.66<T<1150.00$ \\
\hline & ${ }^{0} G_{\mathrm{Te}}^{\text {Hexagonal_A8 }}=-12781.349+174.901226 * T-32.5596 * T * \mathrm{LN}(T)$ & $1150.00<T<1600.00$ \\
\hline
\end{tabular}


Table 2 Continued

\begin{tabular}{|c|c|c|}
\hline Phase or component & Parameter & $T, \mathrm{~K}$ \\
\hline \multirow{8}{*}{$\mathrm{Ag}$} & $\begin{aligned}{ }^{0} G_{\mathrm{Te}}^{\mathrm{Liquid}}= & -17554.731+685.877639 * T-126.318 * T * \mathrm{LN}(T) \\
& +0.2219435 * T * * 2-9.42075 \mathrm{E}-05 * T * * 3+827930 * T * *(-1)\end{aligned}$ & $298.15<T<626.49$ \\
\hline & $\begin{aligned}{ }^{0} G_{\mathrm{Te}}^{\mathrm{Liquid}}= & -3165763.48+46756.357 * T-7196.41 * T * \mathrm{LN}(T) \\
& +7.09775 * T * * 2-0.00130692833 * T * * 3+2.58051 \mathrm{E}+08 * T * *(-1)\end{aligned}$ & $626.49<T<722.66$ \\
\hline & $\begin{aligned}{ }^{0} G_{\mathrm{Te}}^{\mathrm{Liquid}}= & +180326.959-1500.57909 * T+202.743 * T * \mathrm{LN}(T) \\
& -0.142016 * T * * 2+1.6129733 \mathrm{E}-05 * T * * 3-24238450 * T * *(-1)\end{aligned}$ & $722.66<T<1150.00$ \\
\hline & ${ }^{0} G_{\mathrm{Te}}^{\mathrm{Liquid}}=+6328.687+148.708299 * T-32.5596 * T * \mathrm{LN}(T)$ & $1150.00<T<1600.00$ \\
\hline & $\begin{aligned} G_{\mathrm{Ag}}^{\mathrm{FC} \_\mathrm{A} 1}= & -7209.512+118.202013 * T-23.8463314 * T * \mathrm{LN}(T) \\
& -0.001790585 * T * * 2-3.98587 \mathrm{E}-07 * T * * 3-12011 * T * *(-1)\end{aligned}$ & $298.15<T<1234.93$ \\
\hline & $\begin{aligned} G_{\mathrm{Ag}}^{\mathrm{FCC} \_\mathrm{A} 1}= & -15095.252+190.266404 * T-33.472 * T * \mathrm{LN}(T) \\
& +1.411773 \mathrm{E}+29 * T * *(-9)\end{aligned}$ & $1234.93<T<3000.00$ \\
\hline & $\begin{aligned} G_{\mathrm{Ag}}^{\mathrm{Liquid}}= & +3815.564+109.310993 * T-23.8463314 * T * \mathrm{LN}(T) \\
& -0.001790585 * T * * 2-3.98587 \mathrm{E}-07 * T * * 3-12011 * T * *(-1) \\
& -1.033905 \mathrm{E}-20 * T * * 7\end{aligned}$ & $298.15<T<1234.93$ \\
\hline & $G_{\mathrm{Ag}}^{\mathrm{Liquid}}=-3587.111+180.964656 * T-33.472 * T * \mathrm{LN}(T)$ & $1234.93<T<3000.00$ \\
\hline
\end{tabular}

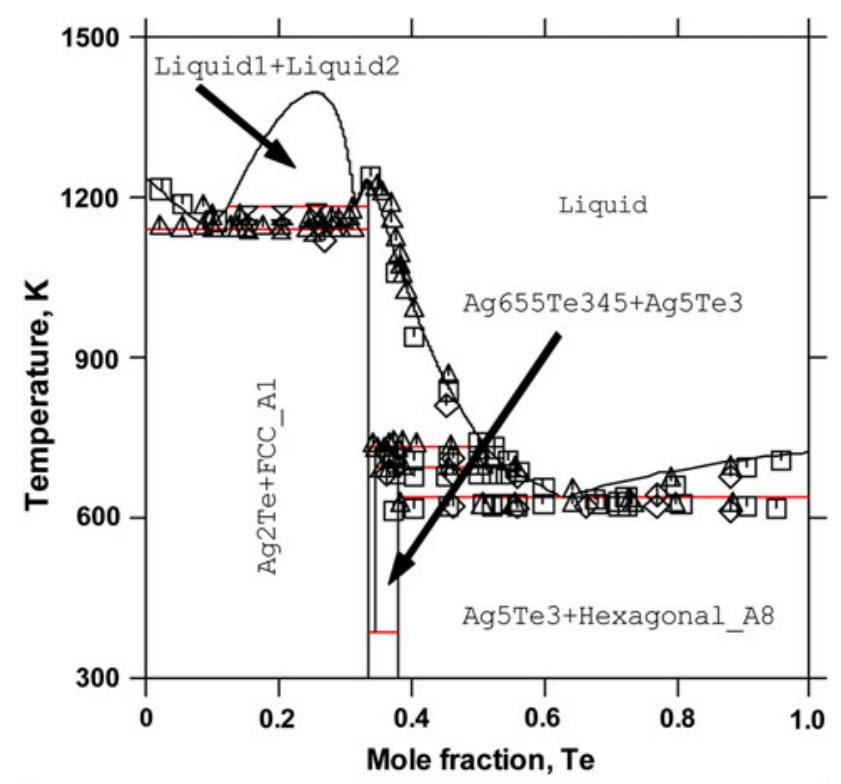

$\triangle$ Kracek et al $\square$ Pelabon $\diamond$ Chikashite and Saito 8 Wobst

Fig. 1 Calculated Ag-Te binary system

binary $\mathrm{Ag}$ - $\mathrm{Te}, \mathrm{Pb}-\mathrm{Te}$ and $\mathrm{Ag}-\mathrm{Pb}$ systems, compared with experimental data obtained by Kracek et al., ${ }^{[17]}$ Pelabon, ${ }^{[18]}$ Chikashite and Saito, ${ }^{[19]}$ Wobst, ${ }^{[20]}$ Fay and Gillson, ${ }^{[21]}$ Moniri and Pelot, ${ }^{[2]}$ Gravemann and Wallbaum, ${ }^{[23]}$ Kharif et al., ${ }^{[24]}$ Kimura, ${ }^{[25]}$ Friedrich, ${ }^{[26]}$ Preckshot $^{[27]}$ and Klep$\mathrm{pa}^{[28]}$ are shown in Fig. 1, 2 and 3, respectively. As can be seen from these figures good agreement between the results of calculations and experimental data was found. The Ag-Te binary diagram has been simplified in this work. Instead of allotropic forms of the $\mathrm{Ag}_{2} \mathrm{Te}, \mathrm{Ag}_{5} \mathrm{Te}_{3}, \mathrm{Ag}_{655} \mathrm{Te}_{345}$, only one

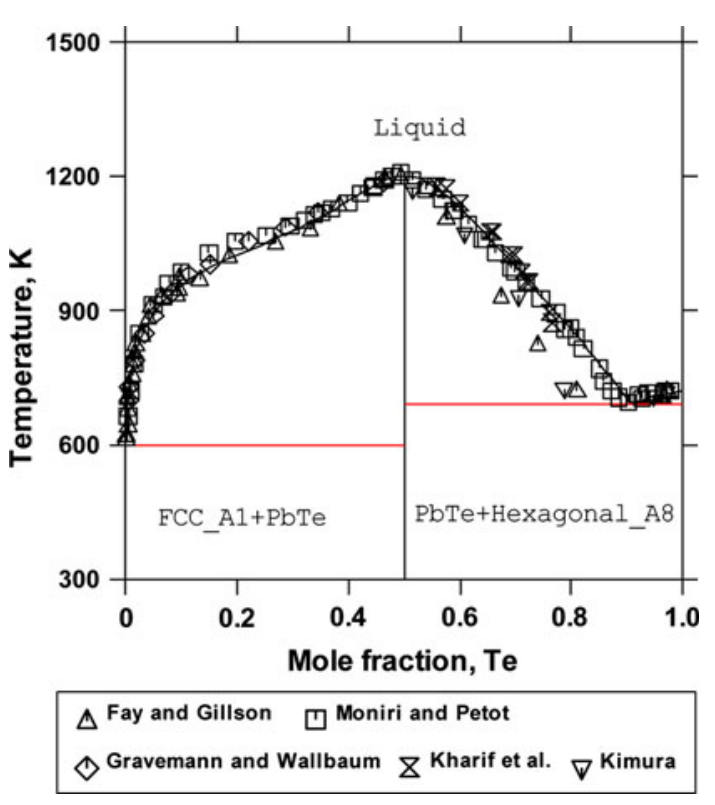

Fig. 2 Calculated $\mathrm{Pb}$-Te binary system

form for each phase was accepted. Following figures show calculated thermodynamic function for the liquid phase in the binary systems. Figure 4 shows the calculated activity of Te in Ag-Te system at $1289 \mathrm{~K}$ superimposed with thermodynamic data obtained by Predel and Piehl. ${ }^{[29]}$ Next Fig. 5 shows calculated enthalpy of mixing of liquid Ag-Te phase together with the experimental results obtained by Castanet et al. ${ }^{[30]}$ Castanet and Bergman, ${ }^{[31]}$ Castanet and Lafitte, ${ }^{[32]}$ Maekawa and Yokokawa, ${ }^{[33]}$ Predel and Piehl. ${ }^{[29]}$ Looking at the comparison of thermodynamic functions with the experimental data as well as the phase diagram one can say 


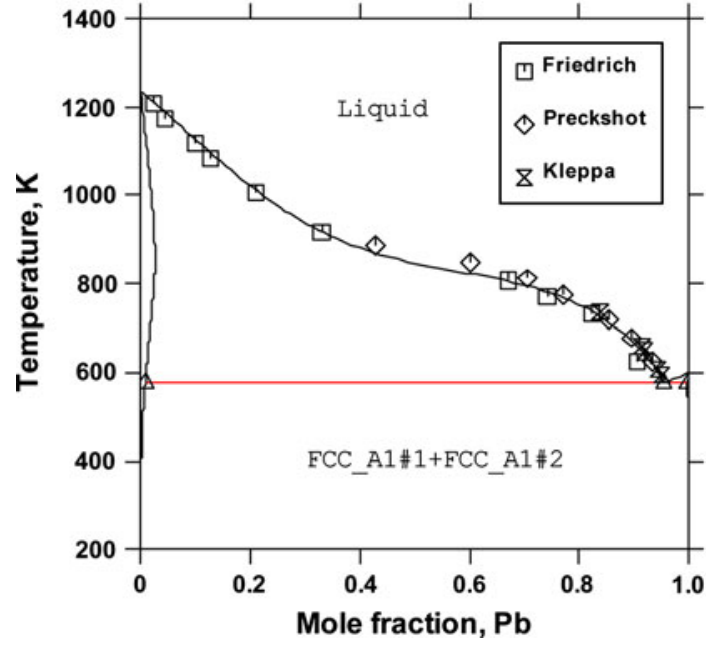

Fig. 3 Calculated Ag-Pb binary system

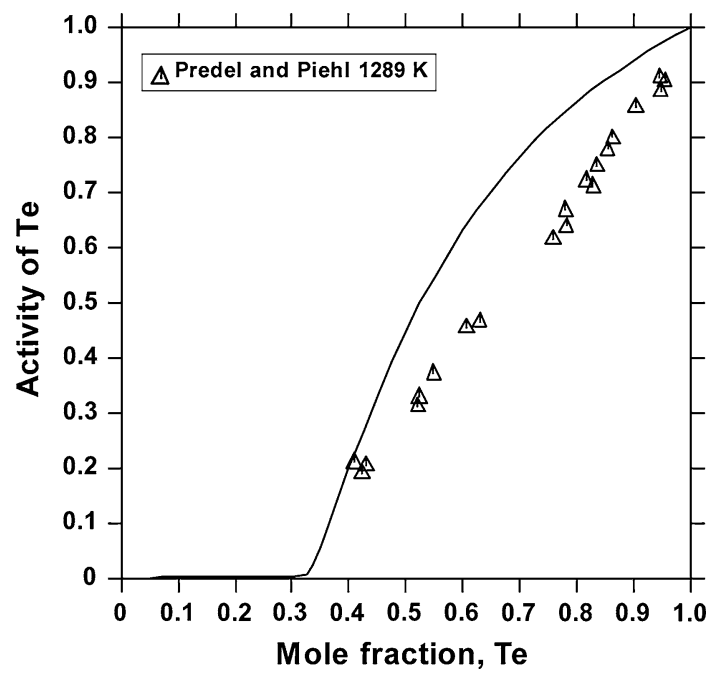

Fig. 4 Calculated activity of tellurium at $1289 \mathrm{~K}$ in the $\mathrm{Ag}-\mathrm{Te}$ system

that associated solution model can be used for thermodynamic modeling of the Ag-Te binary system. Of course, the ionic solution model would be more suitable for tellurium liquid alloys; however, the thermodynamic description will be much more complicated during attempts to describe the ternary system. Calculated enthalpy of mixing of liquid $\mathrm{Pb}$ Te alloys and the chemical potential of $\mathrm{Pb}$ in liquid $\mathrm{Pb}-\mathrm{Te}$ alloy are shown in Fig. 6 and 7 respectively, together with experimental results obtained by Blachnik and Gather, ${ }^{[34]}$ Moniri and Petot, ${ }^{[22]}$ Castanet et al.,${ }^{[35]}$ Maekawa, ${ }^{[36]}$ Predel et al., ${ }^{[37]}$ Brebrick and Strauss. ${ }^{[38]}$ The comparison also shows very good agreement with experimental information found in the literature. The last binary $\mathrm{Ag}-\mathrm{Pb}$ system is an eutectic one. Calculated enthalpy of mixing of the liquid phase, and activity of $\mathrm{Pb}$, are shown in Fig. 8 and 9 respectively. They are compared with the experimental results obtained by Jacob and Jeffes, ${ }^{[39]}$ Castanet et al., ${ }^{[40]}$

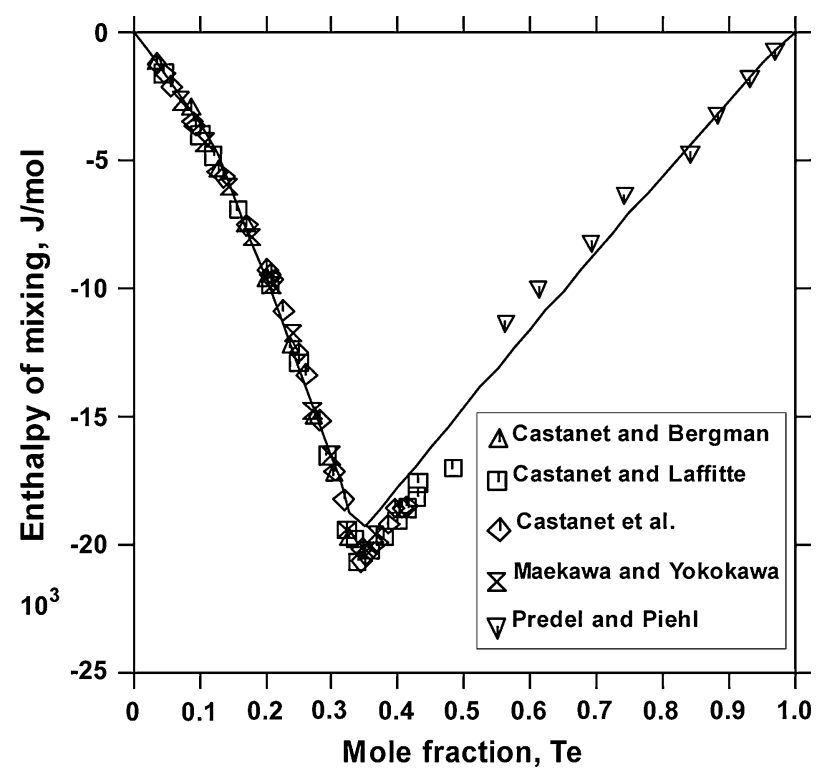

Fig. 5 Calculated enthalpy of mixing of liquid Ag-Te system

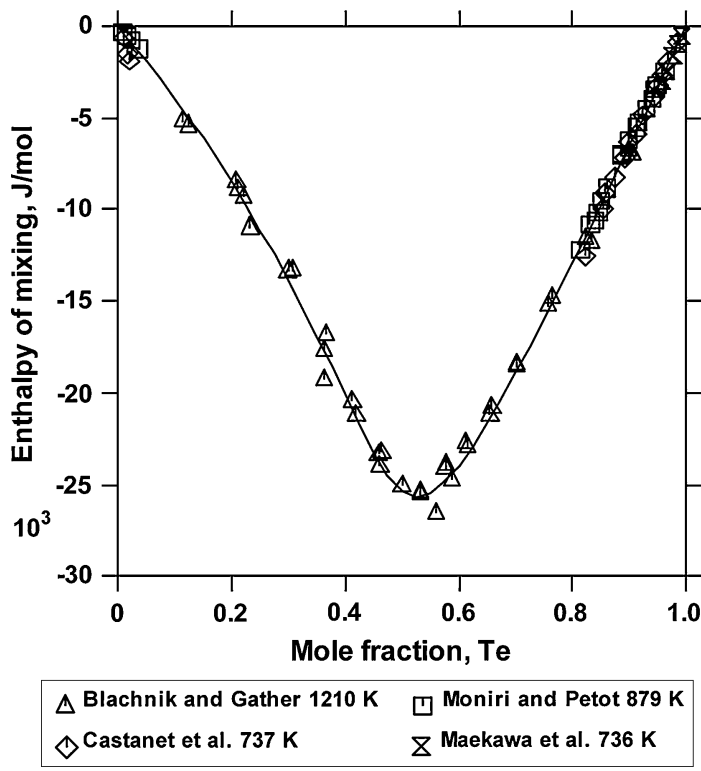

Fig. 6 Enthalpy of mixing of Pb-Te binary system

Itagaki and Yazawa ${ }^{[41]}$ and Hager and Wilkomirsky. ${ }^{[42]}$ Both functions reproduced experimental data very well. It should be mentioned however, that the experimental enthalpy of mixing data show differences between results obtained at similar temperatures.

\subsection{Ternary System}

Since the binary systems show in general very good agreement between the results of calculations and the experimental data, then it's possible to calculate the ternary system using Muggianu interpolation. In the case of Ag- $\mathrm{Pb}-$ Te system it was necessary to optimize some ternary 


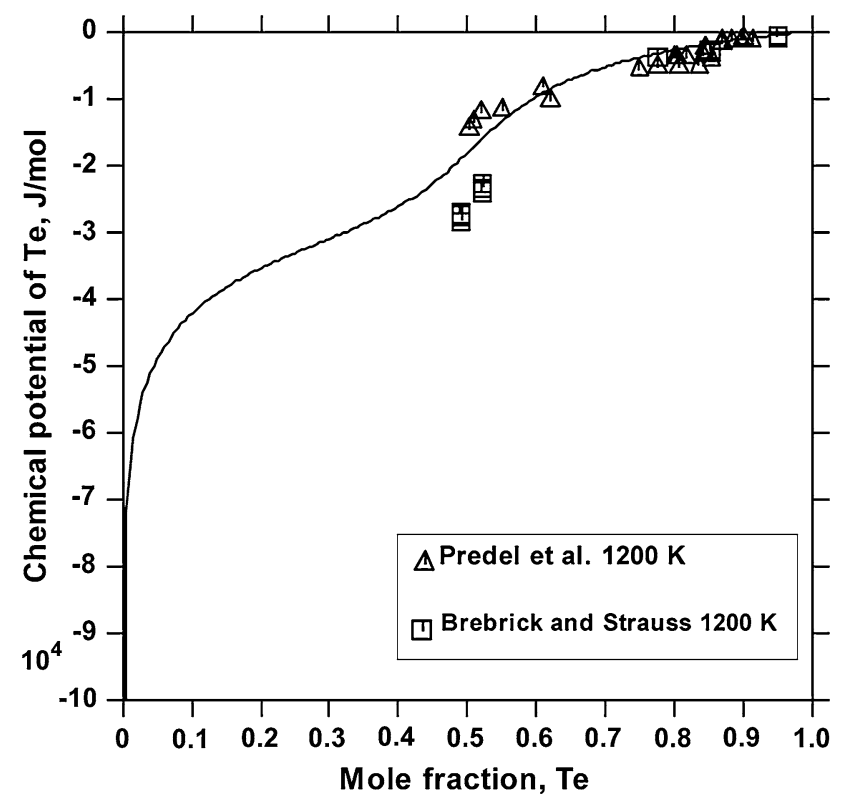

Fig. 7 Calculated chemical potential of Te in liquid Pb-Te alloy at $1200 \mathrm{~K}$

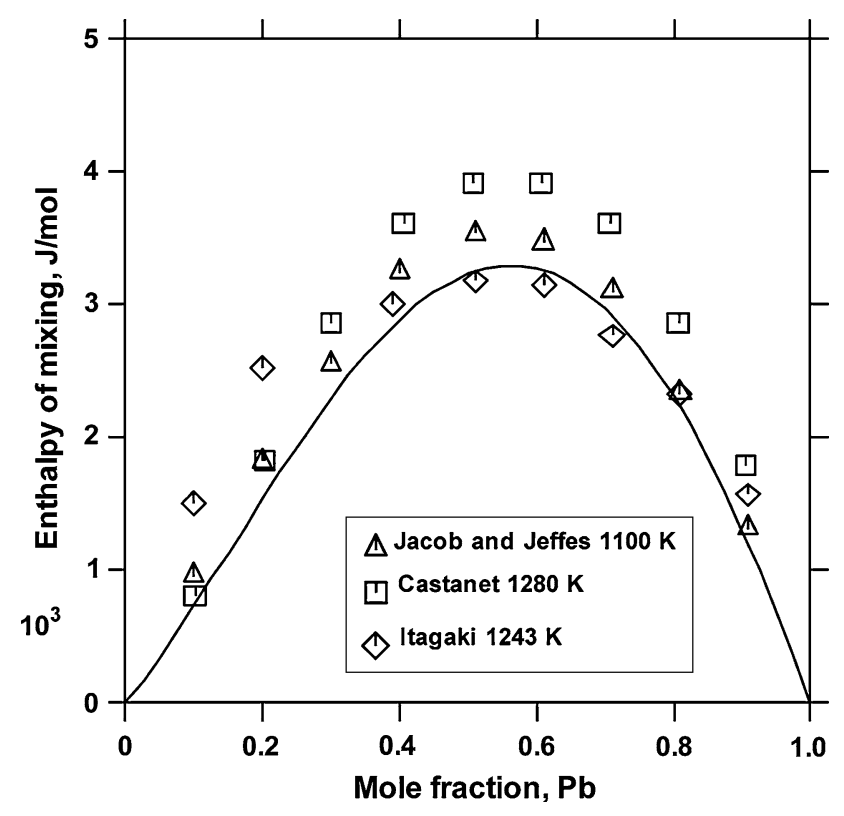

Fig. 8 Calculated enthalpy of mixing of liquid $\mathrm{Ag}-\mathrm{Pb}$ system at $1200 \mathrm{~K}$

parameters. The results are shown in the following Fig. 10, $11,12,13$. The first one, Fig. 10 , shows isopleth $\mathrm{Ag}_{2} \mathrm{Te}-$ $\mathrm{PbTe}$ superimposed with DTA data obtained by Blachnik and Gather. ${ }^{[12]}$ It is clear from this picture that calculated phase equilibria agree well with the experimental data. In turn, Fig. 11 shows the isopleth PbTe-Ag. Again, this isopleth reproduced experimental information given in Ref 13 well. As it was mentioned before, the third available

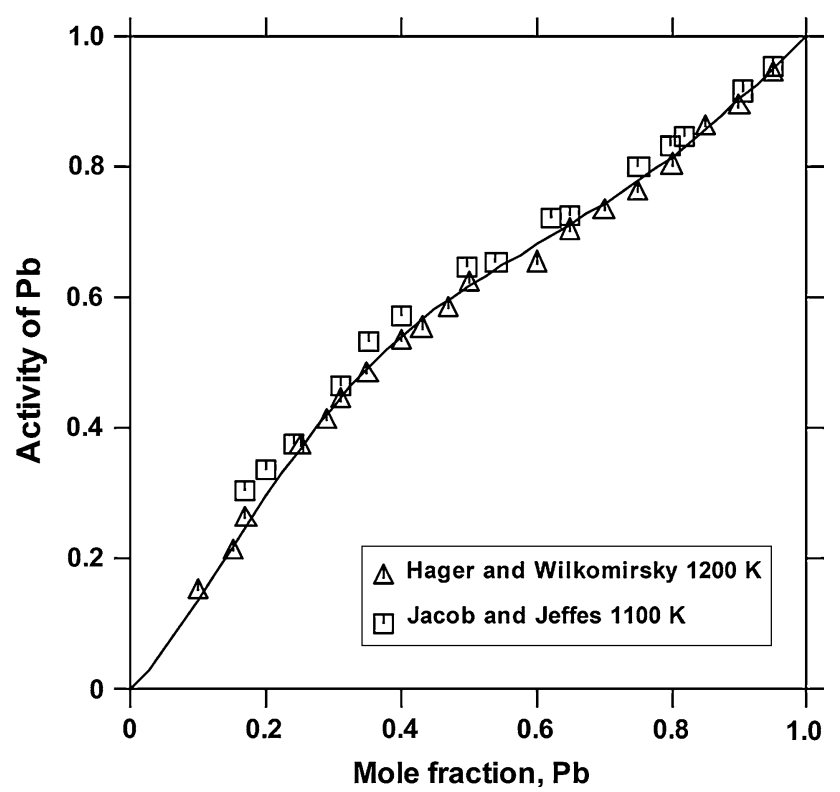

Fig. 9 Calculated activity of $\mathrm{Pb}$ in Ag-Pb binary system

isopleth $\mathrm{Ag}_{2} \mathrm{Te}_{\mathrm{Pb}} \mathrm{Pb}^{[13]}$ does not agree with other experimental data. That isopleth was not used during optimization process and is not shown in this work. Calculated at $1173 \mathrm{~K}$ enthalpies of mixing for two sections $\mathrm{Te}-\mathrm{Ag}_{05} \mathrm{~Pb}_{05}$ and Te- $\mathrm{Ag}_{04} \mathrm{~Pb}_{06}$ are shown in Fig. 12 and 13 respectively. A difference between calculated function and the experimental data $^{[11]}$ is less than $1000 \mathrm{~J}$. In this case we can say that enthalpy of mixing of the ternary $\mathrm{Ag}-\mathrm{Pb}-\mathrm{Te}$ system is reproduced well by our parameters. Figure 14 shows calculated isothermal section at $900 \mathrm{~K}$.

\subsection{Tellurium Vapor Pressure}

Thermodynamic modeling of the ternary $\mathrm{Ag}-\mathrm{Pb}-\mathrm{Te}$ system allows for calculation of tellurium pressure over liquid melts and discussion of lead influence on the tellurium pressure. Gaseous phase of tellurium may contain $\mathrm{Te}, \mathrm{Te}_{2}, \mathrm{Te}_{3}, \mathrm{Te}_{4}, \mathrm{Te}_{5}, \mathrm{Te}_{6}$ and $\mathrm{Te}_{7}$ species; however, the dominant molecule is $\mathrm{Te}_{2}$. The total vapor pressure over liquid tellurium has been determined by Machol and Westrum ${ }^{[43]}$ who described it by the following equation:

$$
\begin{aligned}
\log _{10}(P)= & \frac{-10663.15}{T}+64.7314-18.61687 \log _{10}(T) \\
& +0.00341783 T
\end{aligned}
$$

where $P$ is total pressure of Te over the liquid (pressure given in $\mathrm{mmHg}$ ) and $T$ is temperature in Kelvin.

Using our model of the liquid phase and Machol and Westrum's ${ }^{[43]}$ description of tellurium total pressure, the pressure of tellurium over $\mathrm{Ag}-\mathrm{Pb}-\mathrm{Te}$ liquid alloy was calculated. Result of this calculation is shown in Fig. 15. One can see that pressure of tellurium slightly increases when content of lead in the liquid phase increases up to mole fraction of tellurium smaller than 0.25. However, taking into account the difference between absolute 


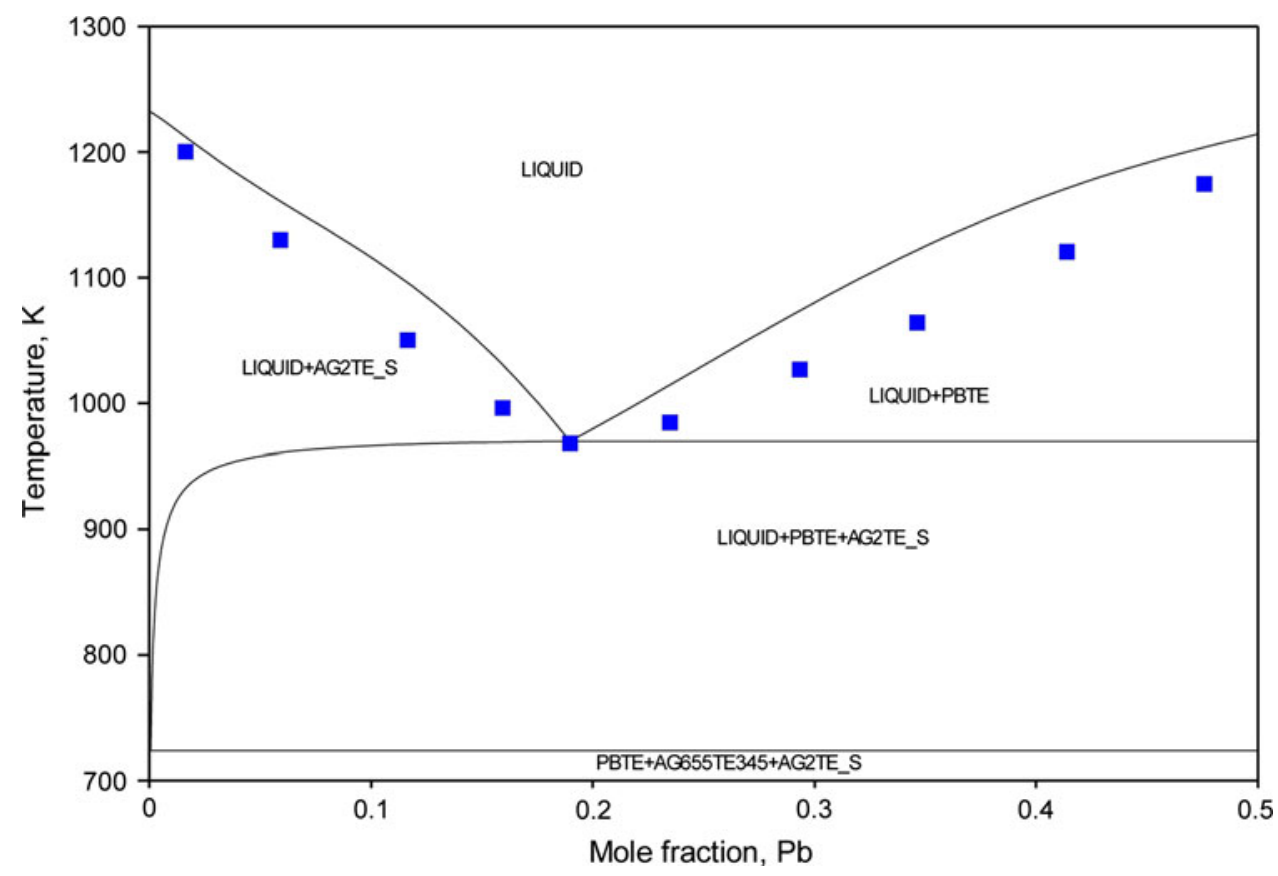

Fig. 10 Isoplethal section $\mathrm{Ag}_{2} \mathrm{Te}-\mathrm{PbTe}$ superimposed with Blachnik and Gather result

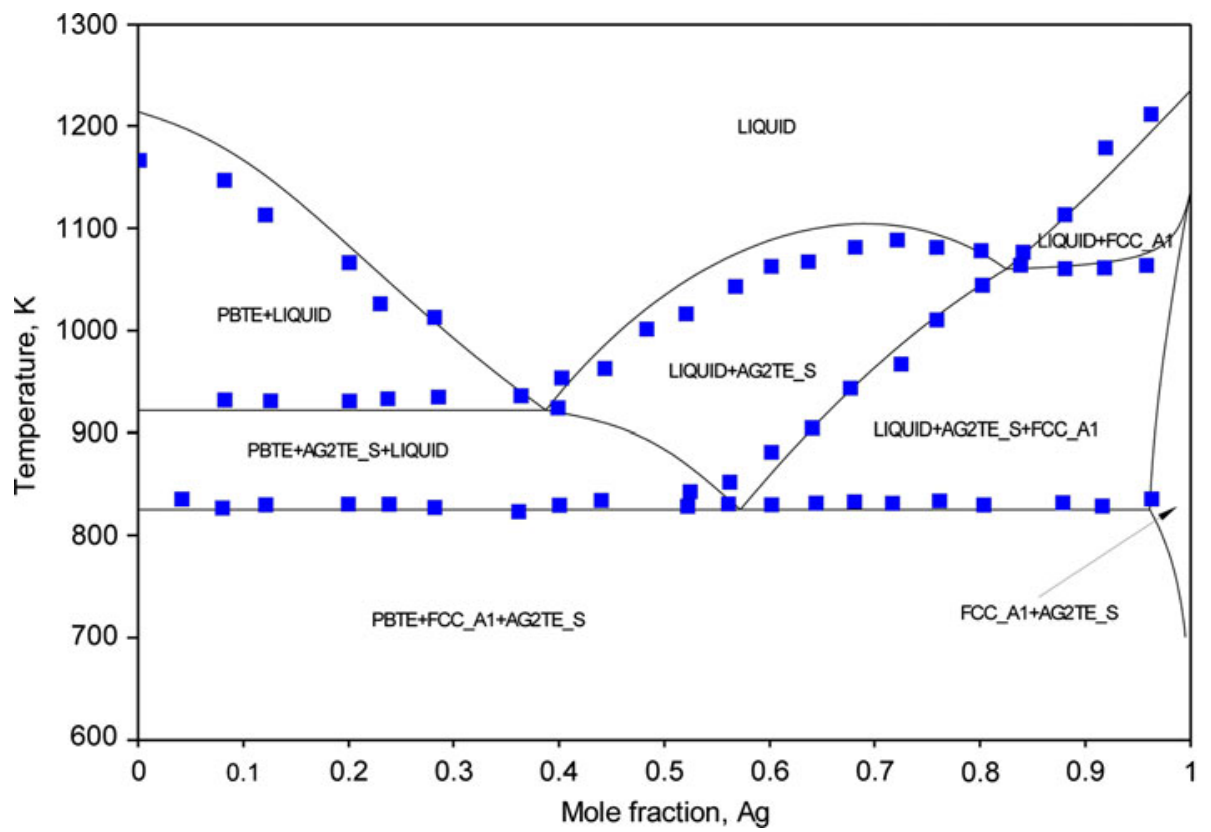

Fig. 11 Isoplethal section PbTe-Ag compared with Romerman and Blachnik results

values of pressures for different amount of $\mathrm{Pb}$ in liquid, one can say that those differences are negligible up to 0.15 mole fraction of Te. The significant differences appear between 0.15 and 0.2 mole fraction of $\mathrm{Te}$ in the liquid phase. The difference cannot be neglected for liquid alloys containing more than 0.2 mole fraction of Te. For this tellurium content and $X_{\mathrm{Pb}}>0.3$, the addition of lead increases pressure of tellurium significantly. It can be explained by smaller interaction between $\mathrm{Ag}$ and $\mathrm{Te}$ when $\mathrm{Pb}$ is added. In other words, the activity of $\mathrm{Te}$ in the liquid 


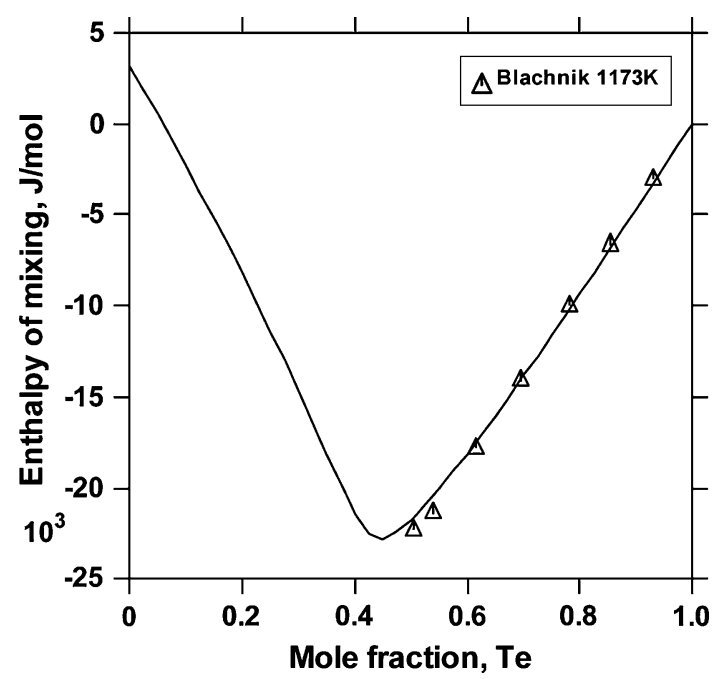

Fig. 12 Calculated enthalpy of mixing of liquid $\mathrm{Ag}-\mathrm{Pb}-\mathrm{Te}$ for the section $\mathrm{Te}-\mathrm{Ag}_{05} \mathrm{~Pb}_{05}$ at 1173 compared with Romermann and Blachnik results

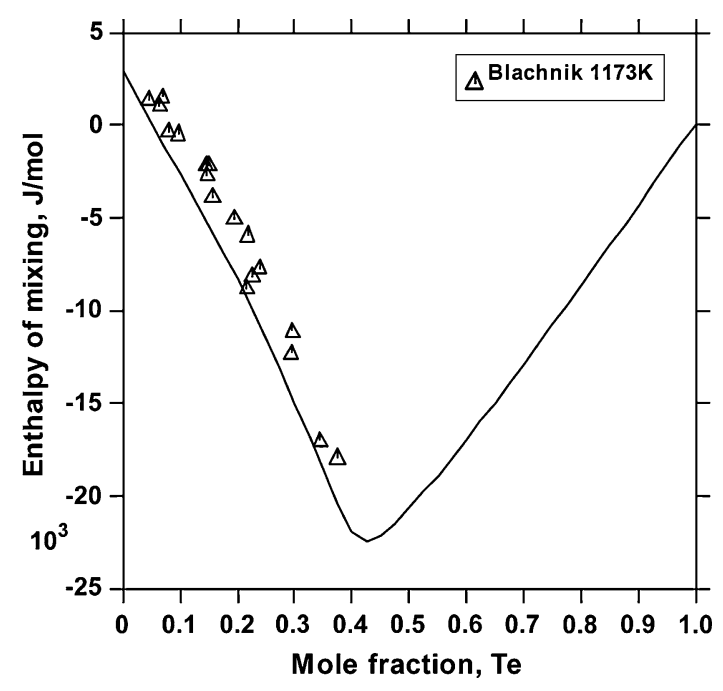

Fig. 13 Calculated enthalpy of mixing of liquid $\mathrm{Ag}-\mathrm{Pb}-\mathrm{Te}$ for the section $\mathrm{Te}-\mathrm{Ag}_{04} \mathrm{~Pb}_{06}$ at 1173 compared with Romermann and Blachnik results

phase becomes less negative when $\mathrm{Pb}$ is added and because of that the pressure of $\mathrm{Te}$ increases, in agreement with Raoult's law.

\section{Conclusions}

The thermodynamic modeling of the ternary $\mathrm{Ag}-\mathrm{Pb}-\mathrm{Te}$ system was performed based on the literature information and a set of thermodynamic parameters was obtained which were then used to reproduce known data. Good agreement between calculations and experimental results was found. With the obtained thermodynamic description of the liquid phase, lead influence on tellurium pressure over Ag-Pb-Te

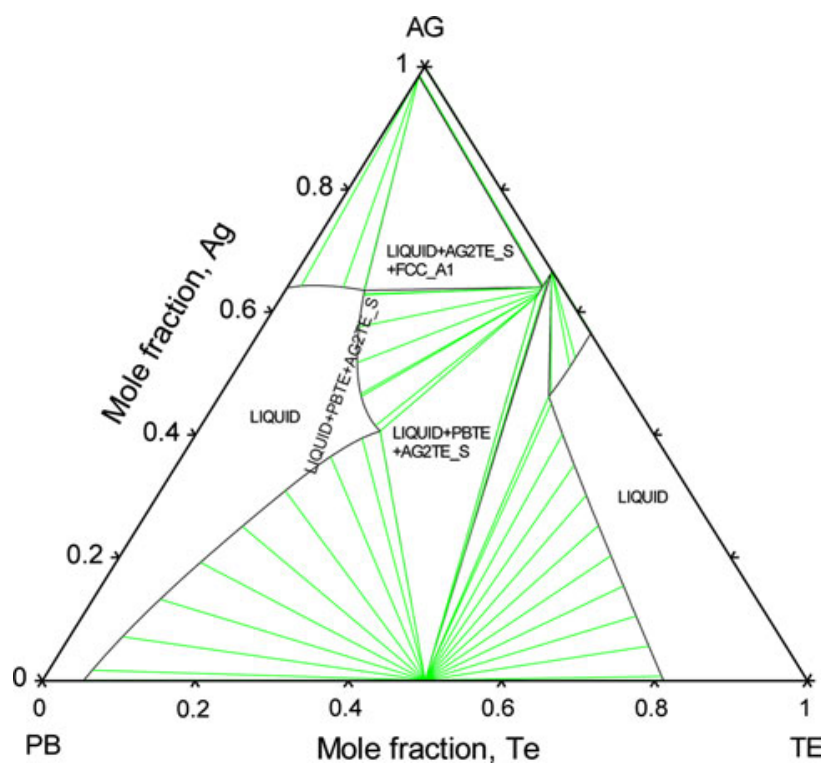

Fig. 14 Isothermal section at $900 \mathrm{~K}$

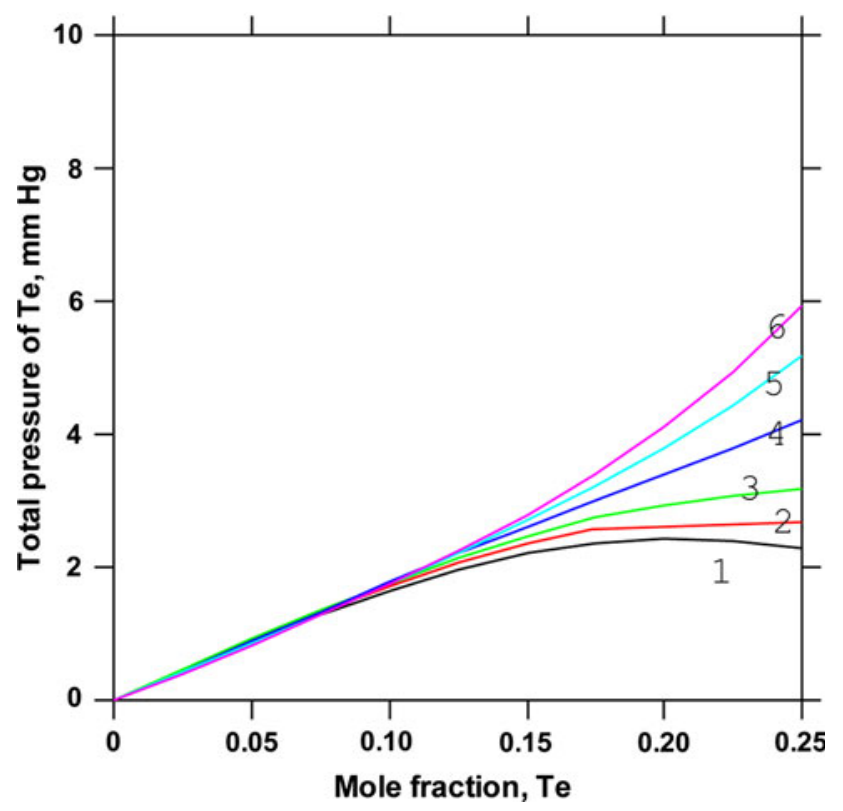

Fig. 15 Total pressure of Te in $\mathrm{mmHg}$ over the liquid phase up to 0.25 mole fraction of Te. $1-\mathrm{AgTe}$ system, $2-6 \mathrm{Ag}-\mathrm{Pb}-\mathrm{Te}$ system: $2-\mathrm{xPb}=0.05,3-\mathrm{xPb}=0.1,4-\mathrm{x}(\mathrm{Pb})=0.2,5-\mathrm{x}(\mathrm{Pb})=$ $0.3,6-\mathrm{x}(\mathrm{Pb})=0.4$

alloys was shows that an increase in lead content of an alloy increases the vapor pressure of tellurium.

\section{Acknowledgments}

The authors are grateful to Narodowe Centrum Badań $\mathrm{i}$ Rozwoju for financial support under grant no. 0364/R/T02/ 2008/04 and to National Taiwan Science Council for financial support under Grant no. NSC-98-2218-E-155-005. 


\section{Open Access}

This article is distributed under the terms of the Creative Commons Attribution Noncommercial License which permits any noncommercial use, distribution, and reproduction in any medium, provided the original author(s) and source are credited.

\section{References}

1. J.E. Hoffman, Recovering Selenium and Tellurium from Copper Refinery Slime, JOM, 1989, 41(7), p 33-35

2. M. Perez-Tello, M.R. Prieto-Sanchez, O. Rodriguez-Hoyos, and V.M. Sanches-Corolles, A Kinetic Model for the Oxidation of Selenium and Tellurium in an Industrial Kaldo Furnace, $J O M, 2004$, 56(12), p 52-54

3. PURE 4.4 SGTE Pure Elements (Unary) Database, Scientific Group Thermodata Europe 1991-2006

4. F. Sommer, Association Model for the Description of the Thermodynamic Functions of Liquid Alloys, Z. Metallkd., 1982, 73, p 72-86

5. E.A. Dancy, Conductivity and Thermopower of Liquid $\mathrm{Cu}-\mathrm{Te}$ Alloys, Trans. AIME, 1965, 233, p 270

6. J.C. Valiant and T.E. Faber, The resistivity and Thermoelectric Power of Liquid Alloys Containing Tellurium, Philos. Mag., 1974, 29, p 571-583

7. V.M. Glazov, S.N. Tshizevskaya, and N.N. Glozdeva, Liquid Semiconductors, Nauka, Moscow, 1967

8. W. Gierlotka, Thermodynamic Assessment of the Ag-Te Binary System, J. Alloys Compd., 2009, 485, p 231-235

9. W. Gierlotka, J. Łapsa, and D. Jendrzejczyk-Handzlik, Thermodynamic Optimization of Pb-Te Using Ionic Liquid Model, J. Alloys Compd., 2009, 479, p 152-156

10. B.-Z. Lee, C.-S. Oh, and D.N. Lee, A Thermodynamic Evaluation of the Ag-Pb-Sb System, J. Alloys Compd., 1994, 215, p 293-301

11. F. Romermann and R. Blachnik, Experimental Investigation and Thermodynamic Calculation of Excess Enthalpies in the Ag-Pb-Te System, J. Alloys Compd., 1998, 280, p 147-157

12. R. Blachnik and B. Gather, Mischungen von GeTe, SnTe und $\mathrm{PbTe}$ MIT $\mathrm{Ag}_{2}$ Te lin Beitrag zur Klärung der Konstitution der Ternären Ag-IVb-Te Systeme $(\mathrm{IVb}=\mathrm{Ge}, \mathrm{Sn}, \mathrm{Pb}), J$. LessCommon Met., 1978, 60, p 25-32

13. R. Blachnik and G. Bolte, Ternary Chalcogenide Systems. VI.-The System Ag-Pb-Te, Z. Metallkd., 1978, 69(10), p 667-672

14. v.R. ThermoCalc, Foundation Computational Thermodynamic, Stockholm, Sweden, 2006

15. R. Schmid-Fetzer, D. Andersson, P.Y. Chevalier, L. Eleno, O. Fabrichnaya, U.R. Kattner, B. Sundman, C. Wang, A. Watson, L. Zabdyr, and M. Zinkevich, Assessment Techniques, Database Design and Software Facilities for Thermodynamics and Diffusion, Calphad, 2007, 31, p 38-52

16. Pandat, CompuTherm LLC, 437 S. Yellowstone Drive, Suite 217 Madison, WI 53719 USA

17. F.C. Kracek, C.J. Ksanda, and L.J. Cabri, Phase Relations in the System Silver-Tellurium, Am. Mineral., 1966, 51, p 14-28

18. H. Pelabon, Sur le Sulfre, le Seleniure, et le Tellure d'argent, C. R. Acad. Sci. (Paris), 1906, 143, p 294-296

19. M. Chikashige and I. Saito, Metallographic Examination of the System Silver and Tellurium, Mem. Col. Sci. Univ. Kyoto, 1916, 1, p 361-368

20. M. Wobst, Verlauf der Mischungslücken der binären Systeme Silber-Tellur, Indium-Tellur, Gallium-Tellur, Thallium-Tellur und Antimon-Selen, Scr. Metall., 1971, 5, p 583-585
21. H. Fay and C.B. Gillson, The Alloys of Lead and Tellurium, Am. Chem. J., 1902, 27, p 81-95

22. M. Moniri and C. Petot, Study and the $\mathrm{Pb}-\mathrm{Te}$ System, J. Calorim. Anal. Therm., 1978, 24b, p 195-201

23. H. Gravemann and H.-J. Wallbaum, Zur Kenntnis des Dreistoffsystems Kupfer-Blei-Tellur, Z. Metallkd., 1956, 47, p 433-441

24. Y.L. Kharif, P.V. Kovtunenko, A.A. Maier, and I.K. Avetisov, Calculation of Phase Equilibrium Diagrams for the $\mathrm{Pb}-\mathrm{Te}$ System on the Basis of the Ideal Solution Approximation, $\mathrm{Zh}$. Fiz. Khim., 1982, 56(9), p 2180-2185, in Russian

25. M. Kimura, On the Phase Diagram of Tellurium with Lead, Mem. Coll. Eng. Kyoto, 1915, 1, p 149-152

26. K. Friedrieh, Blei und Silber, Metallurgie, 1906, 3, p 396

27. G.W. Preckshot and R.E. Hudrlik, Diffusion in the Solid Silver-Molten Lead System, Trans. Metall. Soc. AIME, 1960, 218, p 516

28. J. Kleppa, Thermodynamic Properties of Moderately Dilute Liquid Solutions of Copper, Silver and Gold in Thallium, Lead and Bismuth, J. Phys. Chem., 1956, 60, p 446

29. B. Predel and J. Piehl, Thermodynamic Investigations on Liquid Gold-Tellurium, and Copper-Tellurium Alloys, $Z$. Metallkd., 1975, 66(1), p 33-38, in German

30. R. Castanet and C. Bergman, Calorimetric Investigation of the Liquid Alloys of $\mathrm{Ag}+\mathrm{Te}$ and of the $\mathrm{Ag}_{2} \mathrm{Te}$ Solid Compound at High Temperature, J. Chem. Thermodyn., 1979, 11, p 83-92

31. R. Castanet and M. Laffitte, Intermediate Solid Phases in the Ag-Te System, Rev. Int. Hautes Temp. Refract, 1974, 11(2), p 103-107

32. R. Castanet, Y. Claire, and M. Laffitte, Calorimetric Study of Tellurium and Noble Metal Binary Systems, J. Chim. Phys., 1971, 68, p 1133-1137

33. T. Maekawa and T. Yokokawa, Enthalpies of Infinitely Dilute. Solutions of Transition Metals in Liquid Tellurium, J. Chem. Thermodyn., 1975, 7, p 505-506

34. R. Blachnik and B. Gather, Mixing Enthalpy of the $\mathrm{Pb}-\mathrm{Te}$ System, J. Less-Common Met., 1983, 92, p 207-213

35. R. Castanet, Y. Claire, and M. Laffite, Thermochemical Data Relative to the Tin-Tellurium and Lead Tellurium Systems, High Temp. High Press, 1972, 4, p 343-351

36. T. Maekawa, T. Yokokawa, and K. Niwa, Heat of Dissolution of the Group Ib, IIb, IIlb, IVb and Vb Metals in Fused Tellurium or Selenium, Bussei Kenkyu, 1972, 17, p 282-286

37. B. Predel, J. Piehl, and M.J. Pool, Thermodynamic Properties of Liquid Binary Alloys of Te With $\mathrm{Sn}, \mathrm{Pb}$ and $\mathrm{Bi}, Z$. Metallkd., 1975, 66(6), p 347-352

38. R.F. Brebrick and A.J. Strauss, Partial Pressures in Equilibrium with Group IV Tellurides. I. Optical Absorption Method and Results for PbTe, J. Chem. Phys., 1964, 40, p 3230-3241

39. K.T. Jacob and J.H.E. Jeffes, Activities of Oxygen and Lead in $\mathrm{Pb}-\mathrm{Ag}-\mathrm{O}$ Solutions, J. Chem. Thermodyn., 1971, 3, p 433-443

40. R. Castanet, Y. Claire, and M. Lafitte, Enthalpy of Formation at $1280 \mathrm{~K}$ for Liquid Alloys of Silver with Germanium, Tin, and Lead, J. Chim. Phys., 1969, 66, p 1276

41. K. Itagaki and A. Yazawa, Measurements of Heats of Mixing in Liquid Silver Binary Alloys, J. Jpn. Inst. Met., 1968, 32, p 1294

42. J.P. Hager and I.A. Wilkomirsky, Galvanic Cell Studies Using a Molten Oxide Electrolyte: Part I-Thermodynamic Properties of the Lead-Silver System, Trans. Metall. Soc. AIME, 1968, 242, p 183-189

43. E. Machol and E.F. Westrum, Vapor pressure of Liquid Tellurium, J. Am. Chem. Soc., 1958, 80, p 2950-2952 